\title{
Wall painting in the Roman empire: colour, design and technology Elizabeth Pye
}

Roman wall paintings are frequently admired by visitors to such famous sites as Pompeii and Herculaneum, and traces of them also survive in the remains of many towns and villas throughout the lands of the former empire, but the technological skill of the Roman painters is less widely appreciated. Here the sources of the pigments used and the methods the painters employed to plaster and paint the walls are described.

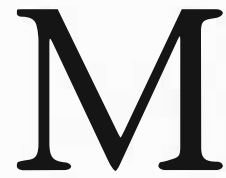
served examples of decorated interiors still in situ are known from Pompeii and Herculaneum on the Bay of Naples, and fragments of decorated plaster, or parts of decorative schemes, have been found in excavated buildings throughout the area formerly covered by the empire. Scholars frequently describe, and sometimes date, the styles of decoration in terms of the types identified at Pompeii, although styles originating in Italy probably took time to reach the provinces and were sometimes modified in the process. Almost all the material referred to in this article takes the form of buried deposits of plaster fragments that resulted from the collapse or demolition of buildings. Some plaster has also remained attached to the footings of walls (Fig. 1).

The study of painted wall plaster can tell us something about the adoption and spread of Roman decorative styles and techniques through the empire. Stylistic analysis focuses on comparison with known examples, such as those at Pompeii, whereas the examination of plaster, fillers and pigments provides understanding of the raw materials and technology, and the ways in which certain surface and colour effects were achieved. Modern analytical techniques, such as polarizing light microscopy (PLM), X-ray diffraction (XRD) and electron-probe microanalysis (EPMA) enable us to identify pigments, to distinguish different pigments present in mixtures, and to discriminate between different layers of colour.

\section{Painting technology}

Lime (calcium carbonate) obtained by heating limestone or marble was used to manufacture the plaster. It had already been used in this way for several thousand years, so the Romans adopted and extended an existing technology. The process involved mixing the lime first with water (to obtain slaked lime) and then with a filler such as sand, before applying it to the wall. Drying and hardening occurred through the evaporation of the water, and reaction with carbon dioxide in the air, to produce lime plaster. The plaster mix was applied in layers, the first of which was usually relatively coarse (containing sand, fine gravel, fragments of pottery) and was applied direct to the wall to provide a level base (Fig. 2). A finer mix that might contain crushed marble to give a translucent white finish was then applied over this base. There could be more than one layer of the coarse plaster and the finer mix, and finally a very thin layer of almost pure slaked lime was frequently applied as a surface preparation. The plaster was also often smoothed and polished, thus giving some painted schemes a particularly fine surface (Figs 3, 4).

Pigments were mixed with water and brushed onto the final plaster layer while it was still fresh and before it had hardened. As the plaster dried, it held the pigments in position, resulting in a durable painted surface. This method of applying pigments is known as the fresco technique. If the painter worked quickly, further detail could be added to the surface before the plaster dried fully; but, once the plaster had set, pigments could be applied successfully only if they were mixed with a lime solution (lime-water) or with an adhesive material such as egg (normally yolk or whole egg) that would hold them in place, a technique known as egg tempera.

The pigments normally used on Roman wall paintings included naturally occurring inert mineral compounds, such as the earth colours (e.g. red and yellow iron ochres and green earth, see below) and carbon in the form of charcoal, because these were unaffected by the highly alkaline lime and by the setting process. The range of colours was extended by the use of Egyptian blue, which was prepared artificially (see below), and of some expensive semi-precious minerals such as cinnabar (which provided a very bright orange red).

\section{Designs}

The decorative designs followed certain conventions. The walls were often divided into three horizontal zones consisting of a dado (a visually distinct zone at the base of the wall), which varied in height between $30 \mathrm{~cm}$ and $90 \mathrm{~cm}$; a main zone approximately three times the height of the ado;

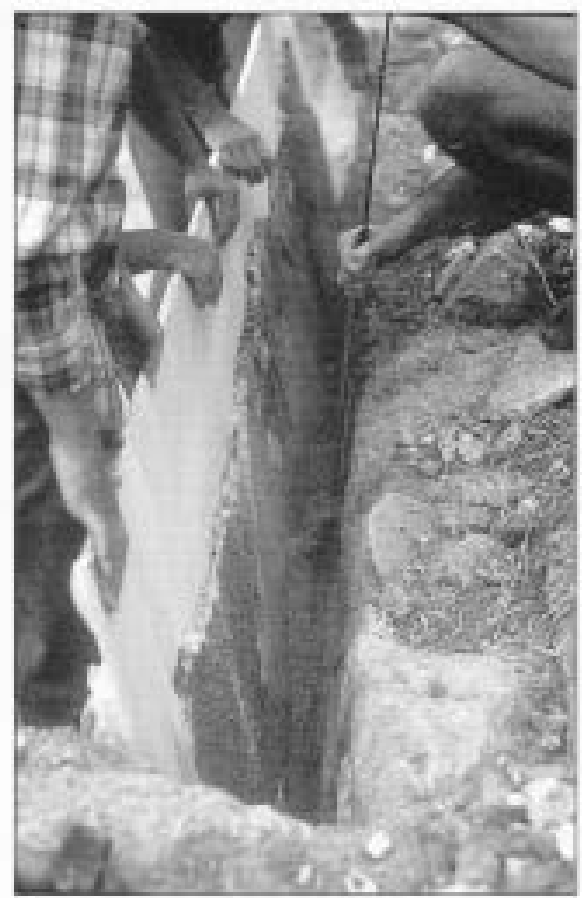

Figure 1 Detaching painted plaster that has remained attached to the stone footings of mudbrick walls at the Roman villa of Sette Finestre, Tuscany, Italy. The plaster has been protected with a cloth facing and as it is detached it is supported against a white board.

and an upper zone just below the ceiling, which varied in size and was not always present. The dado was often decorated to simulate panels of different coloured marbles. The main zone tended to contain the most striking colour or the most detailed design. A common decorative theme in

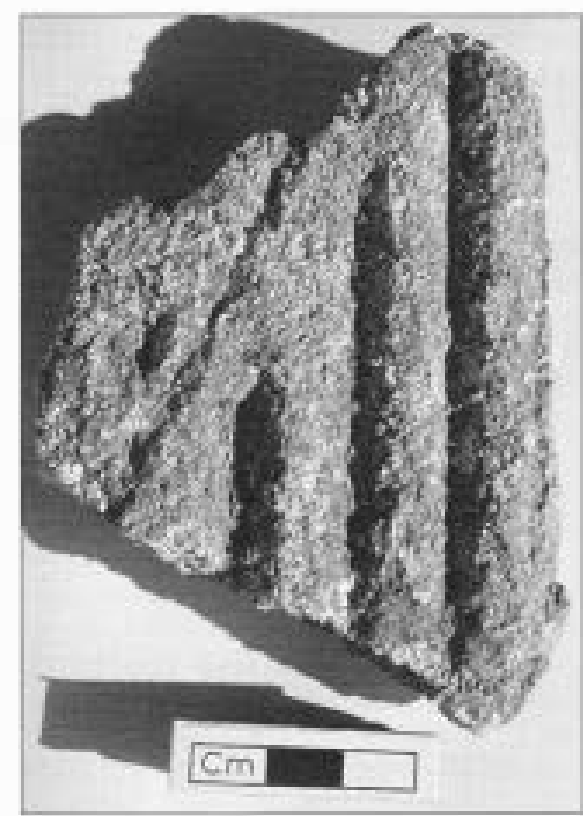

Figure 2 The back of a plaster fragment showing an impression of the wall surface (at the contact between layers ( $e$ ) and (f) as depicted in Fig. 4), Penaflor, southern Spain. 
(a)

(b)

[c]

(d)

(e)

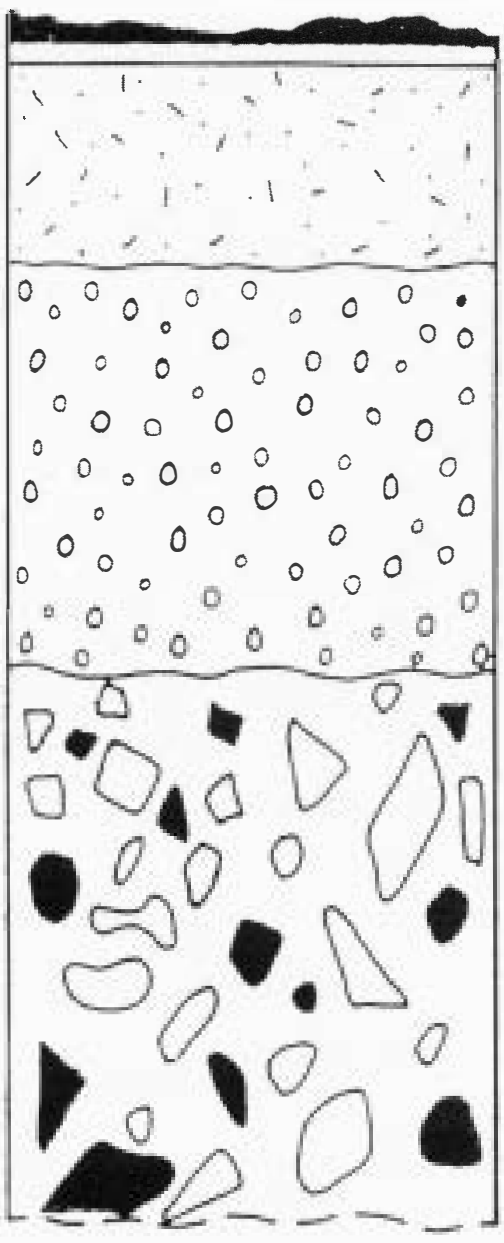

Figure 3 Diagram to show the layered structure of painted wall plaster. (a) The painted surface; (b) layer of pure lime usually 1-2 mm thick, not always present; (c) fine plaster, often less than $1 \mathrm{~cm}$ thick and sometimes mixed with ground marble or other white filler; (d) coarse plaster, often more than $1 \mathrm{~cm}$ thick; (e) preparation layer of plaster of varying thickness, mixed with coarse filler and applied direct to the wall; (f) wall below the plaster layers.

this zone consisted of rectangular or square fields of colour outlined by bands of another colour; the fields might be plain or might contain figurative, architectural or other detail (Figs 5,6$)^{2}$

\section{Itinerant painters}

It is thought likely that much of the decoration was carried out by itinerant painters who carried pattern books showing the currently fashionable designs, and that this accounts for the spread of different styles and for the similarity of decoration in different parts of the empire. Painters may have brought some of their pigments with them, particularly the more unusual or expensive ones, but they could have relied on local sources for the commonly occurring materials such as the ochres.

\section{Local plasterers?}

Lime was used widely for both coarse renderings and fine architectural finishes, so plastering was a well established and much practised technology. ${ }^{3}$ Thus, raw materials for the plaster (lime, sand, etc.) would almost certainly have been obtained locally and a local plasterer may often have mixed and applied the plaster.

For the plasters of finer quality it seems clear that the filler was carefully chosen to produce a particular effect, for example fine white sand in the final plaster layers to produce a white finish, or large translucent inclusions of calcite used in the final layers, which could show through a fine pigment layer and impart a sparkle to the surface. On the other hand, the cruder plasters seem to have been mixed with whatever was available. Certainly, in the range of samples I have examined from different parts of the empire the quality of the plaster varies much more widely than the quality and appearance of the finished painted surface - which conjures up the picture of long-suffering travelling painters sometimes having to produce a good finish on crude and poorly prepared local plasters. This seems to be the case with some British examples, such as the plasters used in the Roman villas at Arundel and Beddingham, Sussex, many of which are very coarse in comparison with examples from the Mediterranean area.,

\section{Sources, use and manipulation of colour}

Although the variation in the quality of the plasters is of interest, perhaps more interesting are the ways in which the painters manipulated a relatively limited palette to produce a range of colours. The basic palette normally included a brownish red (red ochre), a dull yellow (yellow ochre), a greyish green (green earth), black (carbon) and white (lime or another form of calcium or magnesium carbonate). With the exception of carbon black, these pigments all occur naturally and are widely available although there is of ten some variation in their colour (which was sometimes deliberately exploited). They could be used just as they were after grinding and purification, or they could be modified by mixing with other colours, by applying them over an undercoat of another colour, or by changing the colour of the pigment itself, for example by heating it.

Three of these natural pigments owe their colour to iron which is one of the commonest minerals occurring in the Earth's crust. Red ochre (haematite) is hydrated iron oxide and is very widely available. It can vary in colour, depending on the degree of hydration, from a brownish red to a dark purplish red. It is the source of the reddish brown used in Palaeolithic cave paintings and of the socalled Pompeian red found in Roman wall paintings; in fact it occurs in paintings and on artefacts of many different periods and

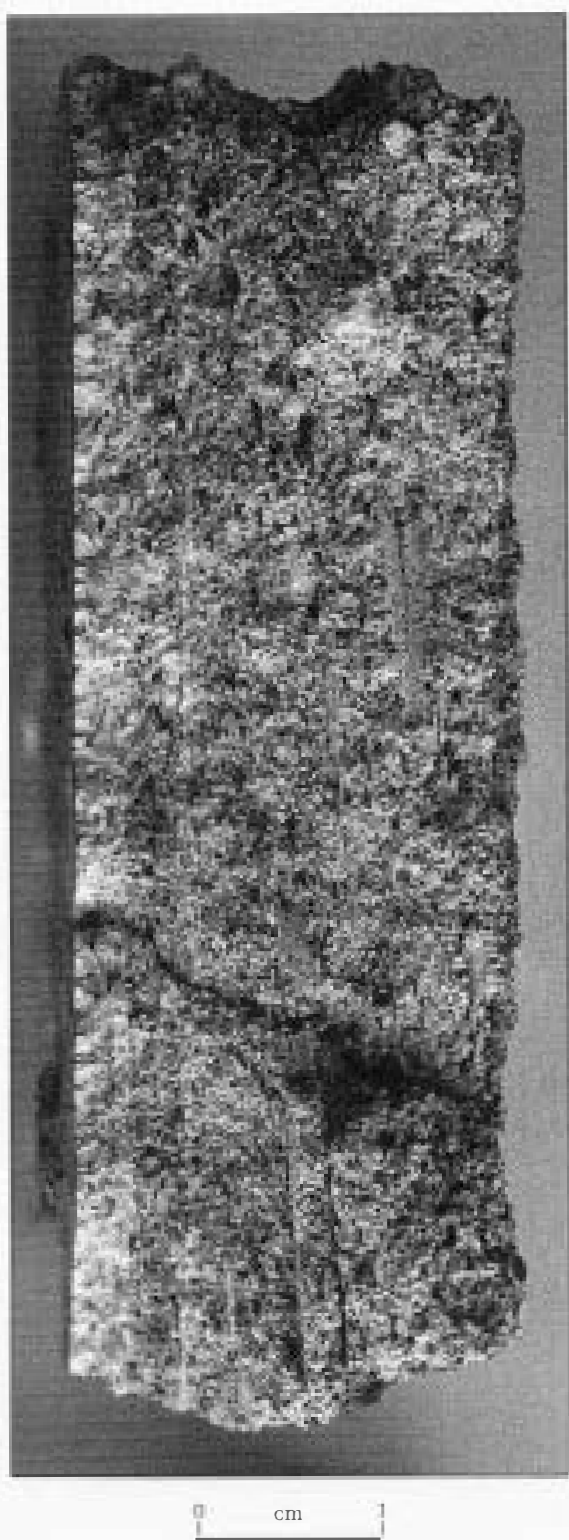

Figure 4 Sectionthroughthe surface layers of plaster of very good quality from Penaflor, southern Spain, showing the use of a fine white filler for the layer (left) nearest the painted surface (extreme left).

cultures. Yellow ochre (limonite) is a yellow form of hydrated iron oxide and is also fairly widely found ${ }^{6}$ Green earth occurs as two clay minerals (celadonite and glauconite), each of which has a significant iron content. The colour is seldom very strong and varies from blueish green to yellowish green, depending on the iron content.?

Carbon black was obtained by charring animal bone or plant matter such as vine twigs. White normally came from some form of calcium or magnesium carbonate. The lime employed to make the plaster could provide a white and was probably sometimes used, but it tended to have poor covering power and to be somewhat translucent when applied in this way as a pigment, so other forms of chalk or limestone were deliberately selected for their ability to produce an opaque white. ${ }^{8}$

The other relatively frequently used 


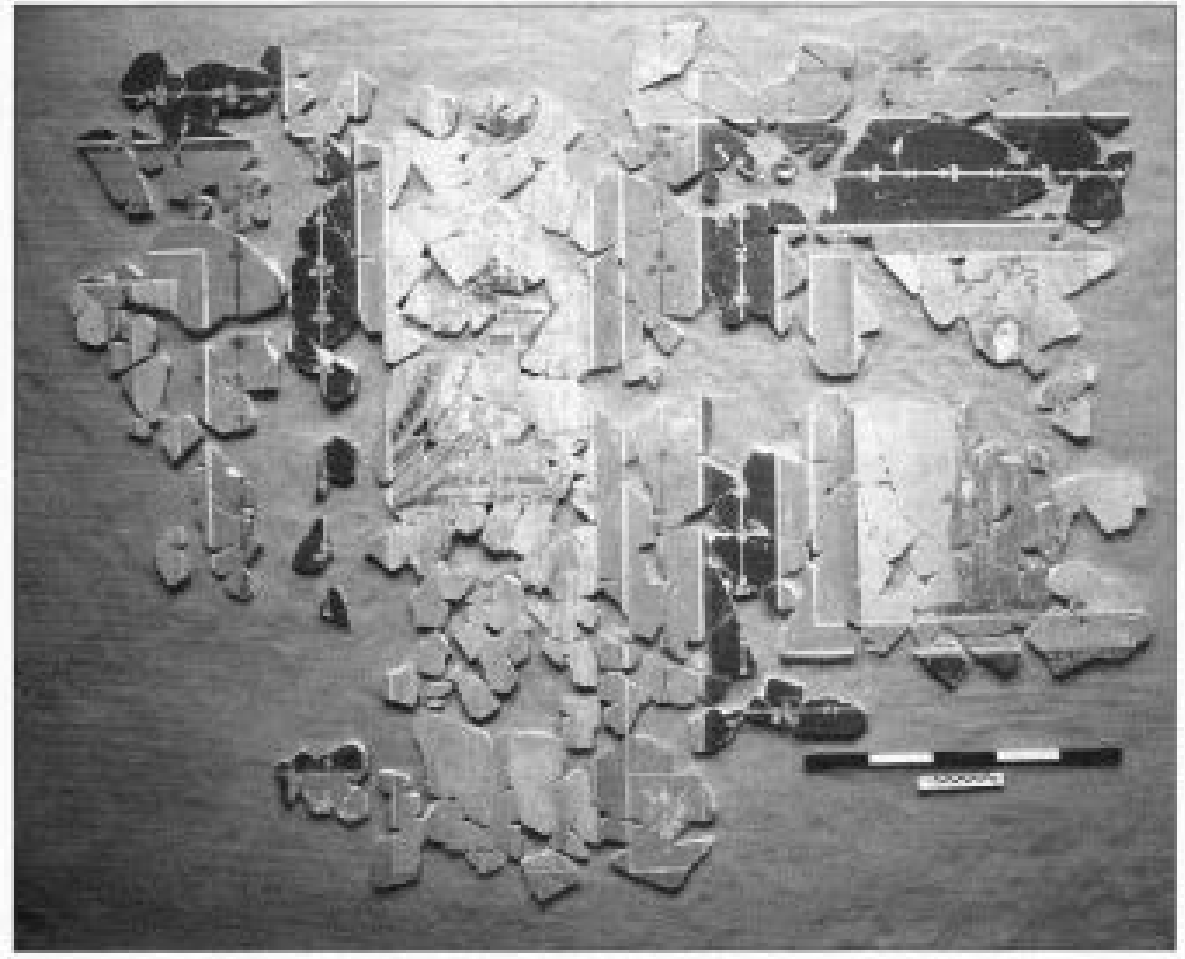

Figure 5 Re-assembled fragments of painted plaster from a Roman house at the site of Sidi Khrebish, Benghazi, Libya, showing part of the design from the main zone of a wall. The design consists of panels outlined in coloured borders and containing figurative and architectural detail (in the so-called Pompeian fourth style). The pigments used include red and yellow ochres, green earth, Egyptian blue and the opt icalblue obtained by mixing carbon black and a white.

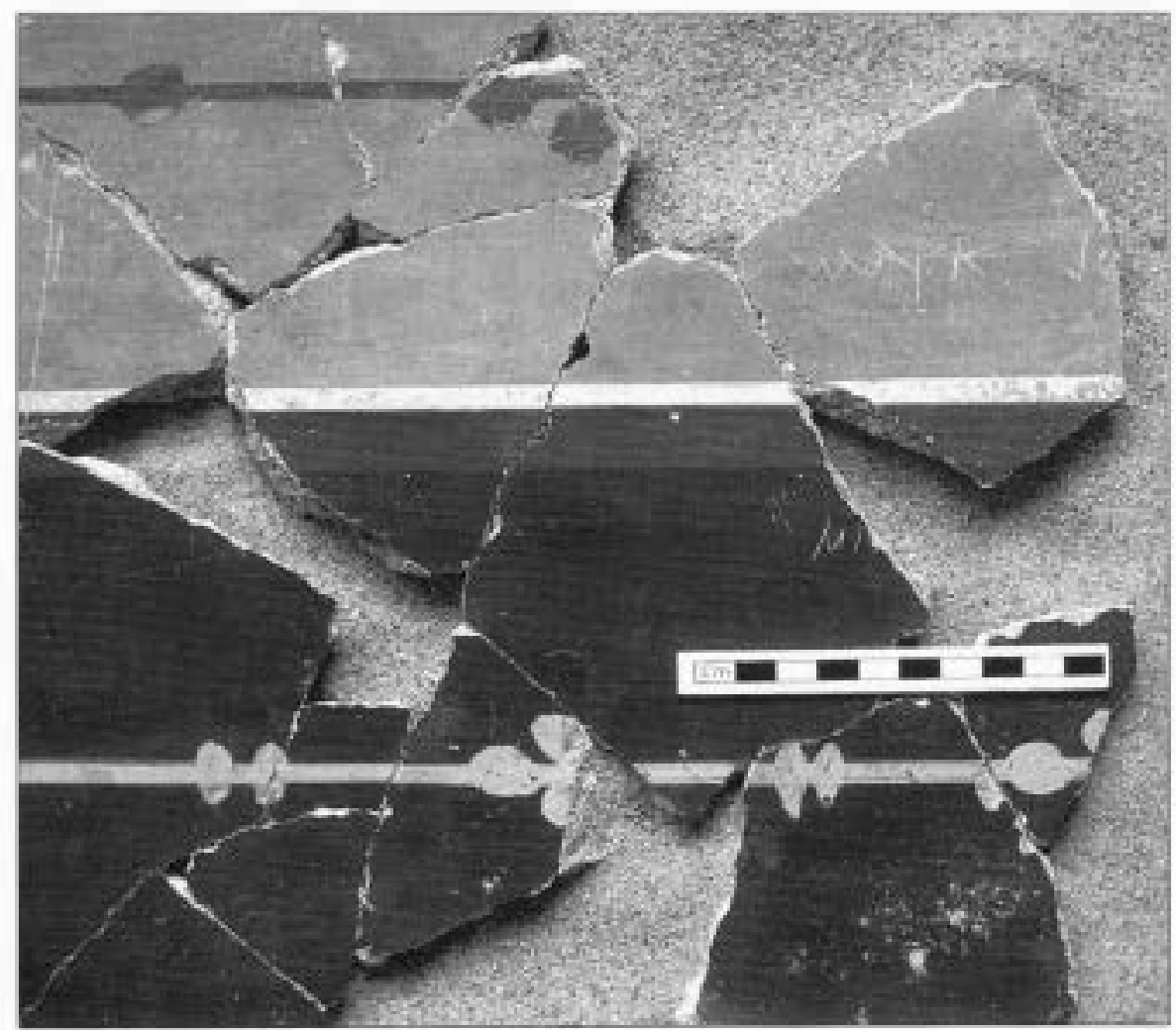

Figure 6 A close-up view of the top right-hand part of Figure 6, showing a type of border design used very widely in Roman wall painting; later Roman graffiti can be seen on the top-right fragment above the white line. colour was a manufactured blue, known as Egyptian blue (technically cuprorivaite, an artificial copper silicate), which derives its colour from its copper content. It was manufactured by heating a mix of copper salts, sand and chalk to produce a blue crystalline compound that provided a pigment with a coarse structure rather like coarse (granulated) sugar. As the name implies, it is found on Egyptian antiquities, but it was also widely used by the Romans. The intensity of the colour depended on the particle size: if ground too finely it loses its clear blue colour and becomes paler and more opaque (just as sugar loses its translucency and becomes opaque white when it is ground to the fine consistency of icing sugar). This property was exploited by the Romans to produce different blues from the same pigment. ${ }^{9}$

Other pigments were also used but tend to be found less frequently, for example cinnabar (red mercuric sulphide) which is known to have been very expensive and so was presumably used only in relatively luxurious decorative schemes. It gives a very bright orange red, which provided striking colour schemes when combined with other colours such as black and green (as seen at the Roman town of Penaflor in southern Spain, Fig. 7). ${ }^{5.1 \bullet}$

Mixtures of different pigments were apparently used either to achieve a different colour or to provide better covering power, or possibly to extend, or substitute for, a pigment that was expensive or difficult to obtain. Thus, white was regularly mixed with other colours, for example with red to produce a pink, or with green to produce a paler colour. Carbon black was mixed with white to produce an optical blue (a mix with a blue appearance, although not a true blue), probably because Egyptian blue, being a manufactured pigment, was

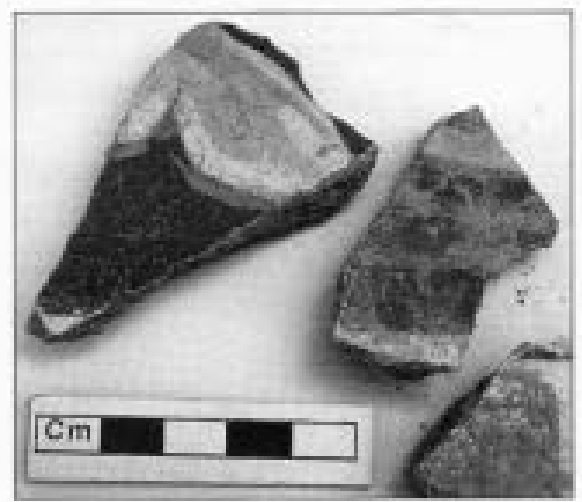

Figure 7 Fragments of plaster painted with vermilion, with foliage details painted in greens consisting of varying mixes of green earth, Egyptian blue and white. The photograph shows three fragments, one of which (left) has been cleaned, revealing that this would have been a magnificent and expensive scheme, probably largely bright red and black, of which tantalizingly few fragments remained. Penaflor, southern Spain. 
more difficult to obtain in quantity and it cost more than the basic earth colours.

The use of an undercoat to increase the covering power or to intensify the colour is perhaps best seen in the habit of applying Egyptian blue over a layer of optical blue, or blue grey, or even almost black (each resulting from mixing different proportions of black and white in the undercoat). Egyptian blue is a glassy substance and the large particles do not cover well. Thus, when applied directly to plaster, it was affected by the white surface to produce a relatively pale blue, whereas when it was applied to a blue-grey undercoat the result was a stronger blue unaffected by the white substrate. The practice of applying expensive blues over cheaper blues continued into medieval and later times, and the choice of the correct undercoat to achieve a strong colour (e.g. on woodwork) is familiar to anyone embarking on interior decoration today. The Romans frequently applied reds over a yellow undercoat, and in the case of cinnabar this practice may have been intended to allow the use of a relatively thin application of this very expensive orange red without losing intensity of colour. ${ }^{5,11}$

It is clear that Roman painters were skilled in using a relatively limited range of pigments to produce subtle and varied effects. The same pigment modifications show up in examples of Roman wall paintings from widely different parts of the empire, which implies that Roman painters shared a common technology. ${ }^{11}$ These modifications are almost certainly part of technical traditions that were developed well before Roman painters used them and they can be seen in later painting techniques, and even in practice today.

\section{Notes}

1. M. Frizot, Mortiers et enduits peints antiques: étude technique et archéologique (Centre de Recherche sur les Techniques Greco-Romaines, Faculté des Sciences Humaines, Université de Dijon, 1975).

2. R. Ling, Roman painting (Cambridge: Cambridge University Press, 1991).

3. See pp. 216-27 in J-P. Adam, Roman building: materials and techniques, translated by A. Mathews (London: Batsford, 1994).

4. Reports by E. Pye with, respectively, M. Abey-Koch and R. Gibbs on the wall plaster used in the Arundel and Beddingham Roman villas will be published in future volumes of Sussex Archaeological Collections.

5. E. Pye, "The wall plaster", in Celti (Penaflor): the archaeology of an Hispano-Roman town in Baetica, S. Keay, J. Creighton, J. Remesal Rodríguez (eds), 124-40 (Oxford: Oxbow, University of Southampton Department of Archaeology Monograph 2, 2000).

6. See p. 122 in R. J. Gettens \& G. L. Stout, Painting materials: a short encyclopaedia (New York: Dover, 1966).

7. C. Grissom, "Green earth”, in Artists' pigments: a handbook of their history and characteristics, volume 1, R. L. Feller (ed.), 141-67 (Washington DC: National Gallery of Art, 1986).

8. H. Béarat, "Quelle est la gamme exacte des pigments romains? Confrontation des résultats d'analyse avec les textes de Vitruve et de Pline", in Roman wall painting: materials, techniques, analysis and conservation, H. Béarat, M. Fuchs,

M. Maggetti, D. Paunier (eds), 11-34 (Fribourg: Institute ố Mineralogy and Petrography, 1996).

9. J. Riederer, "Egyptian blue", in Artists' pigments: a handbook of their history and characteristics, volume 3, E. West Fitzhugh (ed.), 23-45 (Washington DC: National Gallery of Art, 1997).

10. R. J. Gettens, R. L. Feller, W. T. Chase, 1993. "Vermilion and cinnabar", in Artists' pigments: a handbook of their history and characteristics, volume 2 , A. Roy (ed.), 159-82 (Washington DC: National Gallery of Art, 1993).

11. H. Béarat, M. Fuchs, M. Maggetti, D. Paunier (eds), Roman wall painting: materials, techniques, analysis and conservation (Fribourg: Institute of Mineralogy and Petrography, 1996). 